\title{
ГОСУДАРСТВЕННЫЙ БАНК РАЗВИТИЯ КИТАЯ И ЭКСИМБАНК КИТАЯ В ПРОЕКТАХ ФОРМАТОВ АСЕАН+3 И «17+1» В 13-Ю ПЯТИЛЕТКУ (2016-2020 ГГ.)
}

\author{
(c) 2021 Сербина Екатерина Михайловна \\ аспирант Центра экономических и социальных исследований \\ Институт Дальнего Востока РАН, Россия, Москва \\ E-mail: serbinakate@gmail.com \\ Научный руководитель - д.э.н. А.В. Островский
}

В статье анализируется деятельность «политических» банков КНР (Государственного банка развития Китая и Эксимбанка Китая) в проектах форматов АСЕАН+3 и «17+1». Эти платформы являются примерами регионального развития инициативы «Один пояс, Один путь» в Юго-Восточной Азии и странах Центральной и Восточной Европы (ЦВЕ). Концепция АСЕАН+3 нацелена на углубление сотрудничества в т.ч. Китая и стран-участниц АСЕАН, «17+1»- сосредоточена на взаимодействии Китая и стран ЦВЕ. Цель исследования: выявить основные пути и отрасли финансирования, проблемы, пути их решения и потенциал развития.

В связи с тем, что страны-члены АСЕАН занимают лидирующую позицию среди торговых партнеров Китая, а Азия стоит на первой строчке по объему накопленных прямых инвестиций от китайской стороны, Китай активно кредитует проекты в этих странах. Площадка «17+1» наращивает присутствие Китая в торгово-экономической сфере в европейских странах, обладая потенциалом создания альтернативы взаимодействия Китая с Евросоюзом. Финансовые отчетности ГБРК и Эксимбанка, а также статистика государственных ведомств КНР позволяют говорить о том, что эти банки выступают среди ведущих источников финансирования как проектов ПИП в целом, так и в форматах АСЕАН+3 и «17+1».

Автор делает вывод о дальнейшем расширении кредитования Китаем проектов в форматах ACEAН+3 и «17+1», с преобладанием инфраструктурных проектов и проектов в области энергетики, а также увеличении вовлеченности «политических» банков в этот процесс. Китай не ставит задачу извлечения быстрой прибыли, деятельность на данном направлении носит стратегический характер и нацелена на углубление регионального межбанковского сотрудничества, разработку специальных линеек банковских продуктов, завоевание новых финансовых рынков и рынков сбыта, изучение лучших финансовых и производственных практик, накопление опыта ведения крупномасштабных инвестиционных проектов для их осуществления в других странах и регионах мира.

Ключевые слова: «политические» банки; АСЕАН+3; 17+1; Пояс и Путь; 13-я пятилетка; внешние инвестиции; Государственный банк развития Китая; Эксимбанк Китая

\section{1. Вступление}

С момента объявления инициативы «Один пояс, Один путь» (Пояс и путь, ПИП) в 2013 г. «политические»" банки КНР являются одними из основных кредиторов проектов с китайской стороны. С помощью этих финансовых структур правительство Китая осуществляет кредитование как внутри страны, так и за рубежом.

Возрождение древнего Шелкового пути задумывалось как строительство транспортной системы для перевозки грузов из Китая в страны Европы, но мере реализации, ПиП выступает стимулом для становления новых форм международного сотрудничества, посредством вовлечения стран, находящихся на пути, в региональные экономические партнерства. В настоящее время (март 2021 г.) в концепцию ПИП входит Экономический пояс Шелкового пути и Морской шелковый путь XXI века. В Белой книге Информационного бюро Госсовета КНР (10

\footnotetext{
* «Политические банки» КНР - Экспортно-импортный банк Китая, Государственный банк развития КНР и Государственный банк развития сельского хозяйства КНР. Эти банки созданы в качестве инструмента правительства для финансирования крупных проектов, в т.ч. за рубежом. Государственный банк развития Китая входил в число этих банков до 2015 г., в настоящее время входит в число банков развития и выполняет схожие задачи. В статье рассматривается деятельность Эксимбанка Китая и ГБРК.
} 
января 2021 г.) отмечается, что эти два проекта являются «важными общественными благами, предоставляемые Китаем всему миру», ПИП «выступает главной платформой международного сотрудничества в целях развития» [6].

На январь 2021 г. 140 стран и регионов мира входят в ПИП, в 2013-2019 гг. товарооборот Китая со странами ПИП превысил 7,8 трлн. долл., что составляет около 30\% общего объема внешней торговли Китая. В 2020 г. страны АСЕАН стали ведущими торговыми партнерами Китая с объемом в 731,9 млрд. долл., сместив европейские страны (710 млрд. долл.) на вторую позицию [20]. Рост товарооборота Китая со странами Центральной и Восточной Европы (ЦВЕ) в 2020 г. в 8,4\% превысил увеличение товарооборота со странами Европы и составил 103,45 млрд. долл. Этот показатель также выше темпов роста внешней торговли Китая в 2020 г. в целом. Начиная с 2012 г., объем торговли со странами ЦВЕ постоянно увеличивается примерно на $8 \%$ в год, что в три раза превышает темпы внешней торговли Китая в целом, и в два раза превышает темпы роста торговли со странами-членами Евросоюза [15].

Азия сохраняет первое место по объему прямых накопленных инвестиций со стороны Китая (табл. 1) как на конец 12-й пятилетки в 2014 г.601,0 млрд. долл., так и в конце 13-й пятилетки 1460,3 млрд. долл. в 2019 г., увеличившись более чем в 2,4 раза, второе место занимают страны Латинской Америки (рост в более чем 4 раза), третье - Европа - объем инвестиций вырос с 2014 г. по 2019 г. в 1,6 раза достигнув 114,4 млрд. долл. (табл. 1). Объем накопленных инвестиций из Китая в страны ЦВЕ к концу 2020 г. составил 3,14 млрд. долл. Эти факты отражают значимость инициативы для Китая и позволяют прогнозировать дальнейшее стимулирование развития существующих проектов и создания новых в рамках ПИП с фокусом на азиатские страны и налаживание взаимодействия с Европой в региональных форматах - ACЕАН+3 и «17+1».

«Политические» банки выбраны в качестве ведущих финансовых звеньев для инвестирования в проекты ПИП, а также АСЕАН+3 и «17+1» по нескольким причинам: 1) целью их создания в 1994 г. было, в том числе, участие в крупномасштабных проектах, 2) контроль со стороны государственных структур (в первую очередь, Комиссии по регулированию банковской и страховой деятельности КНР) как самих банков, так и сопровождаемых проектов. Вместе с тем, необходимо отметить, что эти финансовые институты не обладают исключительным правом на финансирование проектов ПИП с китайской стороны. Лидером является Фонд Шелкового пути (2014 г.), инвестирует в основном в энергетику, электроэнергию, металлургию [2] и Азиатский банк инфраструктурных инвестиций (2015 г.)[16], также участвует Новый банк развития БРИКС; китайские крупные коммерческие банки с государственным участием (прежде всего, Банк Китая, Торгово-промышленный банк Китая и др.) также входят в проекты, последняя группа в основном принимает участие в синдицированных кредитах и сосредоточена на популяризации юаня в трансграничной торговле.

Таблица 1. Объем накопленных инвестиций в зарубежные страны (всего на конец каждого года, млрд. долл.)

\begin{tabular}{|l|c|c|c|c|c|c|}
\hline \multicolumn{1}{|c|}{ Страна } & 2014 & 2015 & 2016 & 2017 & 2018 & 2019 \\
\hline Индонезия & 6,8 & 8,2 & 9,5 & 10,5 & 12,8 & 15,2 \\
\hline Япония & 2,5 & 3,1 & 3,2 & 3,2 & 3,5 & 4,1 \\
\hline Сингапур & 20,6 & 31,9 & 33,5 & 44,6 & 50,1 & 52,6 \\
\hline Южная Корея & 2,8 & 3,7 & 4,3 & 5,9 & 6,7 & 6,7 \\
\hline Таиланд & 3,1 & 3,5 & 4,5 & 5,4 & 5,9 & 7,2 \\
\hline Вьетнам & 2,8 & 3,4 & 4,9 & 4,9 & 5,6 & 7,1 \\
\hline Азия & $\mathbf{6 0 1 , 0}$ & $\mathbf{7 6 8 , 9}$ & $\mathbf{9 0 9 , 5}$ & $\mathbf{1 1 3 9 , 3}$ & $\mathbf{1 2 7 6 , 2}$ & $\mathbf{1 4 6 0 , 3}$ \\
\hline Латинская Америка & 106,1 & 126,3 & 207,2 & 386,9 & 406,8 & 436,1 \\
\hline Европа & 69,4 & 83,7 & 87,2 & 110,8 & 112,8 & 114,4 \\
\hline Северная Америка & 48 & 52,2 & 75,5 & 86,9 & 96,4 & 100,3 \\
\hline Африка & 32,3 & 34,7 & 39,8 & 43,3 & 46,2 & 44,4 \\
\hline Океания и Австралия & 25,9 & 32,1 & 38,3 & 41,7 & 44,2 & 43,6 \\
\hline
\end{tabular}

*Япония и Южная Корея не являются членами АСЕАН, но входят в концепцию АСЕАН+3.

Составлено по: Чжунго тунцзи няньцзянь - 2020. (На Кит.). (Китайский статистический ежегодник Китая. 2020. Веіјіng. 2020). 
Экспортно-импортный банк Китая (Эксимбанк Китая) и Государственный банк развития Китая (ГБРК) участвуют в проектах как самостоятельно, так и совместно с другими банковскими и небанковскими финансовыми институтами. Например, в составе учредителей Фонда Шелкового пути (с долей в 15 и 5\% соответственно), наряду с Государственным управлением валютного контроля КНР, Китайской инвестиционной корпорацией, которые предоставляют финансирование в размере - $65 \%$ и $15 \%$, соответственно. Наряду с общей для двух банков задачей по выдаче льготных кредитов, существует и специализация (табл. 2).

Китай внутри инициативы ПиП организует со странами-участниками более узкие форматы сотрудничества, формирующиеся по географическому признаку, а, следовательно, объединяющие страны, схожие примерно по культурным и социальным параметрам, что является важными факторами при осуществлении мульти национальных проектов, предполагающих вовлеченность нескольких сторон. Примерами являются форматы АCЕАН+3 и «17+1». В проектах, осуществляемых под эгидой данных платформ активно участвуют «политические» банки, развивая сотрудничество в области межбанковского кредитования, корреспондентских отношений, документарных операций, а также выполняя задачу по интернационализации юаня.

\section{2. Деятельность «политических» банков в рамках АСЕАН+3}

Концепция АСЕАН+3 стала результатом инициации процессов интеграции в Юго-Восточной Азии в формате АСЕАН, этот блок был создан внутри АСЕАН в 1997 г. с целью расширения сотрудничества АСЕАН - Китай, АСЕАН - Южная Корея, АСЕАН - Япония. В связи с интенсификацией торгово-экономических связей со странами-членами АСЕАН Китай активно про- двигает проекты в рамках концепции АСЕАН+3, используя в качестве источников финансирования ГБРК и Эксимбанк Китая. Финансирование направлено на укрепление сотрудничества в различных индустриях, преимущественно в инфраструктуре, кооперации промышленного потенциала, финансового взаимодействия, развития совместных промышленных парков за рубежом, малого и микробизнеса.

\section{1. Проекты с участием ГБРК}

В конце 12-й и в 13-ю пятилетку ГБРК предоставил значительный объем финансирования для стран АСЕАН, основу составили вложения в инфраструктурные и энергетические проекты. В 2015 г. ГБРК выделил 330 млн. долл. на финансирование четырех причалов порта г. Коломбо на Шри-Ланке общей длиной 1200 м и площадью 58 га, способных принимать на отгрузку-погрузку в год 1,56 млн. стандартных 20-ти футовых контейнеров [9].

ГБРК в 2015 г. выделил Индонезии льготный кредит сроком на 40 лет для покрытия $75 \%$ общей стоимости (5,29 млрд. долл.) строительства высокоскоростной железной дороги ДжакартаБандунг. Магистраль позволит сократить время в пути с 4-х часов до 2-х часов, $60 \%$ кредита предоставляется в долларах под $2 \%$, остальная часть - в юанях под 3,4\%. План заявлен как модель инфраструктурного проекта для дальнейшего повторения в других странах. В 2017 г. ГБРК выдал долгосрочный кредит для строительства китайской-индонезийского индустриального парка Morowali в Индонезии, общая сумма заЙма - 1,168 млрд. долл. В 2019 г. ГБРК участвовал в подготовке планов по выработке государственной стратегии сотрудничества Китая с Индонезией под эгидой ПИП. Банк планирует участвовать в инфраструктурных проектах в рамках индонезийского проекта «Региональный комплексный экономический коридор» и разви-

Таблица 2. Кредитная специализация ГБРК и Эксимбанка Китая

\begin{tabular}{|l|l|}
\hline ГБРК & Эксимбанк \\
\hline выдача коммерческих и льготных кредитов и & преференциальное кредитование и страхование \\
открытие кредитных линий, & экспортных кредитов, \\
инвестиционная поддержка, & кредитование покупателей экспортной продук- \\
финансирование экспорта, & ции, кредитование продавцов экспортной продук- \\
предоставление денежных средств для суверенных & ции, \\
заемщиков (МВФ), & льготное кредитование (не менее 50\% экспортоо- \\
управление кредитными рисками, & риентированное), \\
вливание госкапитала, & коммерческие кредиты и линии, \\
дополнительное кредитование под залог (pledged & инвестиционная поддержка зарубежных проектов, \\
supplemental lending, PSL). & установление потолка задолженности для стран, \\
& вливание госкапитала, \\
& дополнительное кредитование под залог. \\
\hline
\end{tabular}


тии стран субрегиона Ланьцанцзян-Меконг.

Для развития инициативы ПИП ГБРК не только предоставляет кредиты, но и укрепляет сотрудничество с банками стран АСЕАН, государственными структурами и сферой торговли. При содействии ГБРК и банков стран-членов АСЕАН в 2010 г. была создана Межбанковская ассоциация Китая и стран АСЕАН [10], в 2019 г.- Межбанковская ассоциация стран АCЕАН+3, организуются семинары для укрепления международного сотрудничества и обмена опытом. В 2019 г. ГБРК также провел серию обучающих семинаров для сотрудников государственных органов и бизнеса во Вьетнаме, Камбодже и Мьянме, о том, как финансирование устойчивого развития может сделать вклад в региональную экономику.

ГБРК инвестирует в нефтеперерабатывающий комплекс в заливе Пулау-Муара-Безар (Бруней), проект предполагает развитие возможностей страны для самостоятельного производства нефтепродуктов, что позволит получать большие доходы от их экспорта по сравнению с сырой нефтью. К концу 2018 г. объем финансирования со стороны китайского банка составил 570 млн. долл. Ожидается, что прибыль Брунея от проекта составит 5,5 млрд. долл., проект со3даст около 100 рабочих мест, что будет способствовать увеличению занятости населения.

\section{2. Проекты с участием Эксимбанка Ки-} тая

В странах - участницах АСЕАН Эксимбанк, как и ГБРК, кредитует в приоритетном порядке инфраструктуру. С 2007 г. участвует в финансировании плотины Джатигеде (Индонезия), объем кредитов от китайского банка покрывает 90\% стоимости проекта, 10\% - правительство Индонезии. Дамба является второй крупнейшей дамбой в Индонезии и обладает мощностями по орошению 90 тыс. га сельхозугодий. В 2017 г. банк выдал кредит на строительство завода по изготовлению солнечных панелей китайской компании Jinko Solar в Малайзии [11].

Эксимбанк также выступает в качестве кредитора с китайской стороны строительства 418-километровой железной дороги для соединения Куньмина (столица юго-западной китайской провинции Юньнань) и Вьентьяна (столица Лаоса). Стоимость проекта - 6 млрд. долл., 60\% из которых покрывает Китай, остальные - правительство Лаоса, предполагается завершить к декабрю 2021 г.

В 2016 г.- Эксимбанк профинансировал ре- конструкцию шоссе № 76 в Камбодже, прокредитовав на сумму в 51,9 млн. долл., связавшую провинцию Ратанакири с остальной страной, финансируются строительство угольной электростанции в Бангладеш Payra Power Plant в объеме 1,9 млрд. долл. [19], это 80\% от общего объема финансирования, остальную часть предоставляет правительство Бангладеш. China General Nuclear Power Group с помощью кредита от Эксимбанка купила энергетическую компанию в Малайзии - Edra Company.

В 2017 г. Эксимбанк профинансировал строительство моста «Дружба», соединившего несколько островов Мальдивов [13], значительно улучшив там транспортное сообщение. Банк прокредитовал удлинение железной дороги на юг Шри-Ланки, соединившей столицу г. Коломбо и порт Хамбантота. В декабре 2017 г. Китай взял в долгосрочную аренду (на 99 лет) порт Хамбантота, что значительно улучшило развитие логистических каналов между двумя основными портами Шри-Ланки. В 2018 г. в г. Ханое начало работу легкое метро на 12 станций, на этот совместный вьетнамско-китайский проект Эксимбанк выдал кредит в размере 250,6 млн. долл. [17].

Особое внимание к кооперации со странами АСЕАН отражается и в том, на каком уровне проводятся переговоры об углублении межбанковского взаимодействия. В марте 2019 г. председатель совета директоров Эксимбанка Китая г-жа Ху Сяолянь встречалась с вице-премьером Сингапура Тарманом Шанмугараном. Стороны заявили о намерениях совместного финансового сотрудничества по инвестированию в Юго-Восточную Азию в рамках организации Infrastructure Asia [14]. Это государственная структура, цель создания которой правительством Сингапура подразумевает финансирование инфраструктурных проектов в ЮВА.

Эксимбанк является «якорным» спонсором Фонда инвестиционного сотрудничества Китая и АСЕАН, учрежденного в 2010 г. с объемом в 10 млрд. долл. и находящегося под прямым контролем Госсовета КНР и Комиссии по развитию и реформам КНР.

В ноябре 2018 г. делегация Эксимбанка посетила форум Азиатских экспортно-импортных банков в Таиланде. Банк стремится налаживать контакты с банками ACEAН с целью совместного финансирования проектов и межбанковского кредитования, создания специальных продуктов и услуг для клиентов в АСЕАН, об этом го- 
ворил вице-президент Эксимбанка Нин Юн во время участия в 16-й Экспо Китай - АСЕАН в сентябре 2019 г.

3. Деятельность «политических» банков в рамках платформы «17+1».

«17+1»- платформа для взаимодействия Китая и стран Центральной и Восточной Европы, существующий с 2012 г. Секретариат расположен в г. Пекине, у каждой страны есть свой национальный координатор, ежегодно проводятся саммиты для обмена информацией и опытом. Кооперация нацелена на укрепление торговоэкономических связей, инвестиций, кооперации в сфере науки, образования и культуры. Для Китая такой формат сотрудничества представляет собой успешный пример «копирования», практикуемого в процессе не только изготовления продукции, но и являющегося частью действий по перениманию лучших практик в различных сферах, умении увидеть и взять лучшее, реализовав в более приемлемом для себя формате. В данном случае речь идет о модели Евросоюза, являющегося прообразом концепции «17+1»**.

\section{1. Платформа «17+1» и ГБРК}

На платформе «17+1» расширяется сотрудничество и в финансово-банковской сфере. В 2017 г. ГБРК создал Межбанковскую ассоциацию Китая и стран Центральной и Восточной Азии. Первоначальный объем финансирования организации со стороны ГБРК составил 2 млрд. евро. Целью создания ассоциации во время выступления на 6-м саммите глав правительств в формате «16+1» в Будапеште премьер Госсовета КНР Ли Кэцян назвал «предоставление кредитов на проекты развития в рамках международного финансового сотрудничества» [7]. Кроме того, Китай выделил 1 млрд. долл. в счет созданного совместного государственного Фонда инвестиционного сотрудничества Китая и стран ЦВЕ. Баланс кредитов ГБРК на конец 2017 г. в проекты «16+1» составлял 20 млрд. евро.

Китай стимулирует страны к вхождению в формат посредством расширения инвестиционного и иных видов кооперации. Кроме того, реализация проектов в данном регионе способствует увеличению числа стран-участниц платформы. В январе 2021 г. стало известно о вхождении в формат «16+1» Греции, которая стала 17-й страной-участницей. Не последнюю роль сыграл и факт значительных финансовых вложений с китайской стороны. ГБРК кредитует китайскую компанию COSCO, участвующую в строительстве третьего терминала Пиренейского порта (Греция). К 2019 г. объем предоставленных банком средств превысил 299 млн. евро. Порт частично уже более десяти лет эксплуатируется китайской стороной. Еще в 2009 г. Греция сдала в аренду часть порта компании COSCO сроком на 35 лет. В 2019 г. ГБРК подготовил доклад «Исследования о сотрудничестве Китая и Греции в приоритетных районах». Такие примеры свидетельствуют о высоком потенциале сотрудничества, которые придает Банк, а, следовательно и китайское правительство взаимодействию с Грецией, логичным продолжением которого стало вхождение Греции в формат «16+1».

ГБРК укрепляет и взаимодействие с банками развития ЦВЕ. Например, в 2017 г. ГБРК совместно с Венгерским банком развития выделил кредит в 1 млрд. евро венгерской химической компании BorsodChem для строительства линии для производства хлора [10].

\section{2. Платформа «17+1» и Эксимбанк Ки-} тая

Эксимбанк Китая также выступает ключевым финансовым партнером проектов в странах ЦВЕ, в т.ч. в рамках Фонда инвестиционного сотрудничества Китая и стран ЦВЕ, основанного банком в 2013 г. с объемом в 500 млн. долл. На конец 2018 г. через фонд осуществлены инвестиции в 12 международных проектов, связанных с энергетикой, образованием, здравоохранением, телекоммуникациями.

Эксимбанк Китая участвует в кредитовании крупнейшего проекта в ЦВЕ - модернизации железной дороги Белград - Будапешт (320 км). Участок Белград - Будапешт является частью Трансъевропейского коридора X, соединяющего Будапешт и Зальцбург с Салониками и Софией., в т.ч. через Сербию (протяженность - 142,2 км) [22]. Этот проект задумывался в 2014 г. и имеет исключительное значение не только для модернизации транспортной системы внутри ЦВЕ, но и представляет собой важный отрезок на пути перевозки грузов из Китая в Европу.

Китайские компании China Railway и China Communications Construction Company получили право на проведение работ на сербском участке

\footnotetext{
* В мае 2021 г. стало известно о выходе Литвы из формата, однако представительство КНР в ЕС сообщило о том, что китайская сторона не информирована и подчеркнуло, что сотрудничество инициировано обеими сторонами и осуществляется на добровольной основе.
} 
модернизации: Нови Сад - Суботица - Келебия (станция на границе с Венгрией), объем вложений от Эксимбанка Китая на январь 2020 г. составил 943 млн. евро [23]. Предполагаемая дата завершения работ на сербском участке -2022 г.

В апреле 2020 г. было подписано соглашение между Венгрией и Китаем на финансирование венгерского участка дороги (159,4 км) в объеме 2,1 млрд. долл., из которых 85\% предоставляет китайская сторона, остальное - Венгрия. Средства выделены на кредитование участка Шорокшар (Будапешт) - Келебия. Реализовывать проект будет венгерский консорциум CRE, китайские компании China Tiesiju Civil Engineering и China Railway Group. В мае 2020 г. стало известно о том, что Венгрия засекретила проект, ссылаясь на такую необходимость для получения ранее выделенного Эксимбанком кредита [1]. Осуществление проекта на венгерском участке откладывается по причине того, что Венгрия как член ЕС обязана соблюдать правила и регламент EC, предполагающий, например, проведение открытого тендера, в свою очередь китайская сторона зачастую рассчитывает на свое участие, если проект одобрен всеми сторонами на высшем уровне*. Примером последнего может служить встреча в сентябре 2018 г. г-жи Ху Сяолянь с президентом Сербии Александром Вучичем. Несмотря на сложившуюся ситуацию Китай планирует продолжить этот сухопутный маршрут до порта Пирей в Греции, взятого в долгосрочную аренду.

Эксимбанк финансирует эксплуатацию первого экспресса Китай - Европа «Чанань», перевозящего в Европу различную продукцию, от станков до товаров народного потребления. Количество поездок постоянно растет, в 2018 г. поезд совершил 1235 поездок, в 2020 - более чем в два раза до 3720 поездок, объем перевезенных грузов превысил 2,811 млн. тонн, что на 1,6 раза больше, чем в 2019 г.

В общей сложности на апрель 2019 г. ГБРК инвестировал в 600 проектов ПИП с объемом 190 млрд. долл., Эксимбанк вложил в 1800 проектов 149 млрд. долл. Объем валютных кредитов ГБРК остается внушительным на протяжении 13-й пятилетки не подвергается значительным колебаниям, несмотря на тенденцию к уменьшению: 276 млрд. долл. в 2015 г., 277,9 млрд. долл.- 2016 г., 261,7 млрд. долл.- 2017 г., 251 млрд. долл. - 2018 г., 245,6 млрд. долл. - 2019 г. Также ГБРК вкладывает значительные суммы в кредитование проектов ПИП, объем кредитования в 2015 г. составлял 14,9 млрд. долл., в 2017 г.17,6 млрд. долл.

«Политические» банки играют важную роль в экономическом и социальном развитии стран-участниц ПИП, способствуя улучшению промышленности и повышению уровня жизни. Банки успешно продолжают укрепление международного сотрудничества посредством подписания соглашений в рамках имеющихся ассоциаций.

\section{4. Основные выводы и перспективы}

Кредитная стратегия «политических» банков под эгидой ПИП (включая АСЕАН+3 и «17+1») определяется правительством, и политическая выгода превалирует над экономической, в связи с чем банки дают кредиты по ставкам ниже по сравнению с коммерческими банками и с более долгим сроком погашения. Стоимость финансирования (расходы на финансирование) компенсируется вливанием государственного капитала, выпуском облигаций, доступом к дополнительному кредитованию под залог от Народного банка Китая.

«Политические» банки осознают риски невозврата кредитов и предпринимают превентивные меры, например, Эксимбанк устанавливает максимальный размер долга для конкретной страны. Во время второго саммита Шелкового пути (14-15 мая 2017 г.) в своем выступлении вице-президент Эксимбанка Сунь Пин подчеркивал, что «слишком большие кредиты ставят под вопрос устойчивость долга» [24]. ГБРК применяет строгие ограничения на кредитные линии суверенных заемщиков и контролирует концентрацию ссуд.

Кроме того, для решения вопроса с возвратом ссуд, вероятно внедрение схемы, которую китайские банки в настоящее время применяют к предприятиям-должникам в самом Китае. Такие компании должны выпускать акции для погашения задолженности перед банкамикредиторами. [4] В свою очередь, банки получили право на вхождение в советы директоров и правления компаний, на принятия ключевых управленческих и производственных решений, нацеленных на восстановление рентабельности производства, оказания по сути помощи пред-

\footnotetext{
* На сербском участке кроме Китая в проект входит российская компания РЖД. Привлечение третьей стороны позволило сделать проект не только китайско-сербским и начать работы в 2017 г.
} 
приятиям в выплате банкам долгов. На зарубежных рынках китайские банки с мажоритарной долей в проектах и китайские компании, осуществляющие проекты, также смогут постепенно наращивать своей авторитет и не только лидировать в процессе ведения проектов, но и по вопросу возврата кредитов при возникновении такой необходимости. По мнению некоторых экспертов, также возможен сценарий по преобразованию непогашенных ссуд в государственный долг страны, где размещены инвестиции, привилегированный допуск китайских компаний к участию в других проектах в странахдолжниках и соглашения на закупку товаров из КНР в счет покрытия долга.

Вместе с тем главной задачей финансирования проектов ПИП для «политических» банков не ставится получение быстрой прибыли, вице-президент ГБРК г-жа Дин Сянцюнь отмечала на втором саммите Шелкового пути, что «максимизация» прибыли не является целью банка. Вместе с тем она подчеркнула тщательность, с которой отбираются проекты для финансирования [18].

Инфраструктурные и энергетические проекты являются основными для финансирования со стороны политических банков в рамках ACE$\mathrm{AH}+3$ и «17+1». Превалирование инфраструктурных проектов способствует созданию международных транзитных транспортных маршрутов, росту спроса на импорт китайских строительных материалов и экспортных доходов КНР [5]. Энергетические проекты дают возможность получения опыта в создании и эксплуатации в том числе ГЭС и АЭС в самом Китае. Деятельность в данном направлении носит стратегический характер, фокусируясь на завоевании новых рынков сбыта, создании инфраструктуры, использовании проектов в качестве демонстрации примеров сделанной работы для потенциальных заказчиков и партнеров в других странах и регионах мира. Привлечение своих граждан и ресурсов решает для Китая проблему занятости, профессионального применения навыков и возможности получения опыта работы на зарубежных проектах.

Как отмечают некоторые эксперты, популярность кредитов от китайских банков объясняется не только льготными условиями (например, Эксимбанк предоставляет льготные кредиты под 2-3\% с 20-летним сроком погашения и с 10-летним грационным периодом, ГБРК предла- гает коммерческие кредиты под 5\% с 13-летним сроком погашения [21]), но и тем, что заемщики сталкиваются с трудностями получении кредитов в западных коммерческих банках, так как им зачастую сложно успешно пройти процедуру проверки (due diligence), у них недостаточно высокие кредитные рейтинги и / или проекты не слишком оправданы коммерчески.

Интернационализация юаня и расширение валютного сотрудничества являются одними из основных задач инициативы ПИП. В докладе, подготовленном Исследовательским институтом Банка Китая в июле 2020 г. отмечается, что с 2013 по август 2020 гг. наблюдается рост использования юаня в торговле между странами, входящими в ПИП, а также увеличивается число валютных сделок. На 2019 г. объем трансграничных транзакций превысил 2,73 трлн. юаней, что на 32\% больше 2018 г. По словам сотрудника этого института и автора исследования Чжао Сюэцина, уровень принятия и использования юаня в странах ПИП продолжает расти, что демонстрируется в объеме обменных операций с юанем, увеличении безналичных расчетов (клиринг), юань стал одним из важных вариантов резервной валюты в странах ПИП [8]. Логично отметить, что именно китайские финансовые институты представляют собой главную силу в популяризации юаня в странах ПИП, первоначально превращая ее в расчетную валюту в международной торговле, а затем в инвестиционную валюту [3]. У ГБРК наблюдается повышение сальдо по трансграничным ссудам в юанях, с 69 млрд. юаней, в 2015 г., до 95,7 млрд. юаней в 2019 г.

Существует ряд проблем, включая недостаток доверия между странами, низкие суверенные кредитные рейтинги, экономическая целесообразность проектов. Для решения этих и других вопросов необходимо вовлечения всех стран АСЕАН+3 и «17+1».

Можно предположить продолжение межбанковского сотрудничества в форматах АСЕАН+3 и «17+1», несмотря на имеющиеся трудности. Эксперты отмечают, что главная сложность заключается в наличии строгих регламентов для проектов, обязательное прохождение тендера (китайская сторона традиционно полагается на договоренности с правящими силами), участие Китая в проектах предполагает не только финансовые вливания, но и привлечение китайских специалистов и использование китайских материалов и ресурсов, что не всегда привет- 
ствует странами, где происходит такая деятельность по причине потенциальной конкуренции.

Для Китая подобного рода кооперация носит стратегический характер, это способ наладить долгосрочные коммуникации с банковским сектором стран-участниц АСЕАН и ЦВЕ, заявить о себе на финансовых рынках этих стран, разработать и внедрить банковские продукты с региональной спецификой, «застолбить» ме- сто для кредитования определенных секторов экономики (традиционно самых сильных в этих странах на текущий момент и/или перспективных), поближе познакомиться с особенностями и принципами организации местного финансового мира, культурой и менталитетом, накопить опыт в кредитовании межнациональных крупных проектов для того, чтобы предлагать их реализацию на других площадках.

\section{Библиографический список}

1. Венгрия засекретила проект строительства железной дороги Будапешт - Белград. Available at: https:/ www.rzd-partner.ru/zhd-transport/news/vengriya-zasekretila-proekt-stroitelstva-zheleznoy-dorogi-budapeshtbelgrad/

2. Крупномасштабные банки Китая оказывают помощь в строительстве «Одного пояса, одного пути». 23.03.2015. China.org.cn. Available at: http://russian.china.org.cn/exclusive/txt/2015-03/25/content_35151039. htm

3. Новоселова Л.В. Финансовая реформа - ключевое звено 12-й пятилетки // Итоги 12-й пятилетки (20112015 гг.) и перспективы развития экономики КНР до 2020 года / отв. ред. А. В. Островский; сост. П.Б. Каменнов.- М.: ИДВ РАН, 2017.-334. С. 61.

4. Островский A. В. Экономика Китая до пандемии коронавируса: сможет ли Китай построить «общество сяокан» к столетнему юбилею КПК - 2021 г. // Экономика КНР в годы 13-й пятилетки (2016-2020) / Рос. Акад. Наук, Ин-т Дальнего Востока; сост. П. Б. Каменнов; отв. ред. А. В. Островский.- М.: ИДВ РАН, 2020. - 334, С. 14-15. URL.: http://www.ifes-ras.ru/images/abook_file/book-ekknr13-2020.pdf

5. Сазонов С.Л. Автомобильный комплекс КНР: императивы инновационного развития / С. Л. Сазонов. В 2 кн. Кн. 2. Региональный аспект.- М.: ИДВ РАН, 2020.-296 с., Сс. 31-32

6. Гоуюань синьвэнь баньгунши фабу «синьшидай дэ чжунго гоцзи фачжан хэцзо байпишу» [Белая книга Информационного бюро Госсовета КНР «Сотрудничество в области международного развития в новую эпоху». (In Chin.)] Available at: http://www.gov.cn/xinwen/2021-01/10/content_5578615.htm

7. Ли Кэцян цзай дилю цы чжунго - чжундун оу гоцзя линдаожэнь хуэйу шан дэ цзянхуа. [Выступление Ли Кэцяна на 6-м саммите глав правительств в формате «16+1»]. 28.11.2017. Xinhua. Available at: http://www.gov. cn/guowuyuan/2017-11/28/content_5242751.htm

8. Чжао Се цин «жэньминь гоцзихуа гуаньча» 2020-нянь ди 12 ци: “и дай и лу” яньсянь жэньминьби шиюн чжанъай юй дуйсэ цзяньи. [Чжао Сецин «Исследование по интернационализации жэньминьби», № $12,2020$. Барьеры и пути преодоления в процессе использования юаня в инициативе «Один пояс, Один путь»]. Банк Китая. Available at: https:/www.boc.cn/fimarkets/summarize/202007/t20200730_18196446.html

9. Чжунго кайфа иньхан 2015-нянь няньду баогао [Финансовая отчетность ГБРК за 2015 г.], C. 61. Available at: https://pdf.dfcfw.com/pdf/H2_AN201704120497526207_1.pdf

10. Чжунго кайфа иньхан 2017-нянь няньду баогао [Финансовая отчетность ГБРК за 2017 г.] Available at: https:// pdf.dfcfw.com/pdf/H2_AN201911071370496552_1.pdf

11. Чжунго кайфа иньхан 2018-нянь няньду баогао [Финансовая отчетность ГБРК за 2018 г.], C. 50. Available at: http://www.cdb.com.cn/bgxz/ndbg/ndbg2018/

12. Чжунго цзиньчукоу иньхан 2016-нянь няньду баогао [Финансовая отчетность Эксимбанка $3 а 2016$ г.], сс. 50-51. Available at: http://www.eximbank.gov.cn/aboutExim/annals/2016/201806/P020180610508677212813.pdf

13. Чжунго цзиньчукоу иньхан 2017-нянь няньду баогао [Финансовая отчетность Эксимбанка $3 а 2017$ г.], С. 50. Available at: http://www.eximbank.gov.cn/aboutExim/annals/2017/201811/P020190618520171784000.pdf

14. Чжунго цзиньчукоу иньхан 2019-нянь няньду баогао [Финансовая отчетность Эксимбанка Китая за 2019 г.], C. 68. Available at: http://www.eximbank.gov.cn/aboutExim/annals/2017/201811/P020190618520171784000.pdf

15. Шанубу чжаокай лисин синьвэнь фабухуэй [Министерство коммерции КНР проводит регулярную прессконференцию. 04.02. 2021. (In Chin.)]. Available at: http://www.mofcom.gov.cn/xwfbh/20210204.shtml

16. Belt and Road Initiative Overview. Deloitte. Available at: https://www2.deloitte.com/cn/en/pages/soe/articles/ belt-and-road-facts.html 
17. Cat Linh-Hadong metro line to come into commercial operation in 2018. Vietnamnet. 08.01.2018. Available at: https://english.vietnamnet.vn/fms/business/193415/cat-linh-hadong-metro-line-to-come-into-commercialoperation-in-2018.html

18. China Focus: Risks on Belt \& Road loans controllable / Xinhua. Available at: http://www.xinhuanet.com/ english/2017-05/11/c_136274899.htm

19. China funding Payra power plant // Dhaka Tribune Available at: https://www.dhakatribune.com/ bangladesh/2018/04/17/china-funding-payra-power-plant

20. China Economic Monitor. Issue: 2021Q1. Available at: https://assets.kpmg/content/dam/kpmg/cn/pdf/en/2021/02/ china-economic-monitor-q1-2021.pdf

21. Horn Sebastian, Reinhart, Carmen M.; Trebesch Christoph. China`Overseas Lending. Available at: https://www. econstor.eu/bitstream/10419/200198/1/1668908891.pdf

22. Krisztina Than, Anita Komuves. Hungary, China sign loan deal for Budapest - Belgrade Chinese rail project. 24.04.2020. Reuters. Available at: https://www.reuters.com/article/us-hungary-china-railway-loan/hungarychina-sign-loan-deal-for-budapest-belgrade-chinese-rail-project-idINKCN226123

23. Ralev Rdomir. Serbia sings railway overhaul financing deal with China`s Exim Bank. SeeNews. Available at: https:// seenews.com/news/serbia-signs-railway-overhaul-financing-deal-with-chinas-exim-bank-651907

24. Shu Zhang, Matthew Miller. Behind China`s Silk Road vision: cheap funds, heavy debt, growing risk. Available at: https://www.reuters.com/article/us-china-silkroad-finance-idUSKCN18B0YS 